\title{
Management of Acute Subdural Hematoma: Single-centre Experience with 20 Subjects
}

\author{
Mustafa Efendioğlu1, (1) Esra Adıyeke² \\ ${ }^{1}$ Department of Neurosurgery, Haydarpasa Numune Training and Research Hospital, Istanbul, Turkey \\ ${ }^{2}$ Department of Anesthesiology and Reanimation, Şehit Prof. Dr. İlhan Varank Training and Research Hospital, Istanbul, Turkey
}

\begin{abstract}
Introduction: Given the high morbidity and the mortality that arise from the acute subdural hematoma (ASDH), factors affecting the clinical and neurological outcomes need to be clarified. This retrospective study purposes of demonstrating a single-center experience of the surgical treatment of subjects with ASDH and aims to find out to the contributors to the in-hospital mortality in subjects with ASDH.

Methods: This retrospective study analyzed data of 20 subjects who underwent surgical evacuation of an acute subdural hematoma. Data concerning demographic features and pre-and postoperative hemodynamic parameters were retrieved from electronic medical records.

Results: The median length of the intensive care unit (ICU) stay was seven (2-28) days. In-hospital mortality occurred in four (20\%) subjects. Correlation analyses revealed that intraoperative mean arterial pressure was significantly correlated with inhospital mortality ( $r=-0.565, \mathrm{p}=0.009)$.

Discussion and Conclusion: In our study population, the mortality from surgical management of the ASDH was 20\%, which is quite lower than the reported mortality rate in previous studies. Intraoperative mean arterial pressure was a significant contributor to in-hospital mortality. Rapid and vigorous management of the intraoperative hypotension may improve the surgical outcomes in subjects with ASDH.

Keywords: Acute subdural hematoma; arterial pressure; mortality; surgery.
\end{abstract}

A cute subdural hematoma (ASDH), which is located between the dura and arachnoid membranes, is a neurosurgical emergency that usually arises from the injury of the bridging veins that extend from the surface of the brain to the dural sinuses ${ }^{[1]}$. Most of the ASDH cases, fortunately, arise from the low-pressure veins so that elevation of the intracranial pressure may facilitate the formation of a clot tamponade and eventually terminate the bleeding [2]. However, 25 to $30 \%$ of the ASDHs are estimated to arise from arterial rupture.
Many of the cases with ASDH are traumatic in origin; however, treatment with antiplatelet agents or anticoagulants, arteriovenous malformations, and rupture of an intracranial aneurysm may also lead to the development of ASDH [3-5]. Spontaneous ASDH may also be encountered in subjects with a history of acute or chronic elevation in blood pressure. Although many guidelines are available to make the decision-making in patients with ASDHs simpler, the weakness of the evidence supporting these guidelines obligates individualizing the management of these patients.

Correspondence (İletişim): Mustafa Efendioğlu, M.D. Haydarpasa Numune Egitim ve Arastirma Hastanesi, Norosirurji Anabilim Dali, Selimiye, Tıbbiye Cad No: 23, 34668, Istanbul, Turkey

Phone (Telefon): +90 2165423232 E-mail (E-posta): drefendioglu@gmail.com

Submitted Date (Başvuru Tarihi): 23.11.2019 Accepted Date (Kabul Tarihi): 25.11.2019

Copyright 2019 Haydarpaşa Numune Medical Journal

OPEN ACCESS This is an open access article under the CC BY-NC license (http://creativecommons.org/licenses/by-nc/4.0/) 
Non-surgical management is reserved for subjects with smaller ASDHs in patients in good neurologic conditions or in patients with large ASDHs, causing a minimal mass effect ${ }^{[6]}$. However, many of the ASDHs require immediate evacuation ${ }^{[7]}$.

Given the high morbidity and the mortality that arise from the ASDH, factors affecting the clinical and neurological outcomes need to be clarified. This retrospective study purposes of demonstrating a single-center experience of the surgical treatment of subjects with ASDH and aims to find out to the contributors to the in-hospital mortality in subjects with ASDH.

\section{Materials and Methods}

This retrospective study analyzed data of 20 subjects who underwent surgical evacuation of an acute subdural hematoma at Sancaktepe Training and Research Hospital between January 2019 and September 2019. Written informed consent was obtained from all subjects. This study was approved by the local ethics committee and was conducted according to the current version of the Helsinki Declaration. Data concerning demographic features, including age, gender, comorbid diseases, American Society of Anesthesiologists Classification (ASA) class, etiology, and pre-and postoperative hemodynamic parameters, were retrieved from electronic medical records.

All subjects underwent standardized general anesthesia. $0.03 \mathrm{mg} / \mathrm{kg}$ of midazolam intravenously was administered for premedication. General anesthesia was induced with intravenous propofol $2 \mathrm{mg} / \mathrm{kg}$, fentanyl $1 \mathrm{mg} / \mathrm{kg}$ and 0.8 $\mathrm{mg} / \mathrm{kg}$ rocuronium and was then maintained with $0.1 \mathrm{mg} /$ $\mathrm{kg} / \mathrm{h}$ intravenous remifentanil. Ventilation was performed in a volume-controlled mode at a tidal volume of 7-9 mL/ $\mathrm{kg}$. Blood pressure, heart rate, and $\mathrm{SaO}_{2}$ were monitored throughout the surgery. Operation time and length of the intensive care unit stay and in-hospital mortality were recorded for all subjects.

\section{Statistical Analysis}

All analyses were performed on SPSS v21 (SPSS Inc., Chicago, IL, USA). Shapiro-Wilk test was used for determining whether variables were normally distributed. The homogeneity of variances was assessed using the Levene test. Data were given as mean \pm standard deviation or median (minimummaximum) for continuous variables concerning normality and frequency (percentage) for categorical variables. The relation for mortality with selected variables was analyzed using Pearson and Spearman correlation analysis. A p-value smaller than 0.05 was accepted as statistically significant.

\section{Results}

A total of 20 subjects who underwent surgical evacuation of an acute subdural hematoma were included in this study. The demographic characteristics of the subjects are given in Table 1. The mean age of the subjects was $56.7 \pm 16.7$, and $65 \%$ of them was male. The majority of the subjects was ASA class II (65\%). The most frequent comorbid disease was hypertension (70\%). $45 \%$ of the ASDHs were traumatic, whereas $35 \%$ of them were associated with hypertension, and $20 \%$ were related to the consumption of anticoagulant or antiaggregant agents.

Hemodynamic parameters are presented in Table 2. The

Table 1. Clinical characteristics of the study population

\begin{tabular}{lc}
\hline & $\mathbf{n = 2 0}$ \\
\hline Age, years & $56.7 \pm 16.7$ \\
Gender, male & $13(65)$ \\
ASA class, n (\%) & \\
II & $6(30)$ \\
III & $13(65)$ \\
IV & $1(5)$ \\
Comorbid diseases, n (\%) & \\
Diabetes & $6(30)$ \\
Hypertension & $14(70)$ \\
COPD & $3(15)$ \\
Coronary artery disease, $\mathrm{n}(\%)$ & $6(30)$ \\
Heart failure & $2(10)$ \\
Malignancy & $3(15)$ \\
Advanced liver disease & $2(10)$ \\
Etiology, n (\%) & \\
Traumatic & $10(50)$ \\
Hypertensive & $7(35)$ \\
Anticoagulant agent & $3(15)$ \\
\hline
\end{tabular}

Table 2. Hemodynamic parameters and in-hospital mortality of the study population

Operation time, $\min$

$48 \pm 8$

Mean arterial pressure (Preoperative), $\mathrm{mmHg}$

$95 \pm 21$

Mean arterial pressure (Intraoperative), $\mathrm{mmHg}$

$87 \pm 17$

Mean arterial pressure (Postoperative), $\mathrm{mmHg}$

$83 \pm 17$

Heart rate (Preoperative), min

$84 \pm 18$

Heart rate (Intraoperative), min

$79 \pm 16$

Heart rate (Postoperative), $\min$

$80 \pm 16$

$\mathrm{SaO}_{2}$ (Preoperative), \%

$95(85-99)$

$\mathrm{SaO}_{2}$ (Intraoperative), \%

98 (94-100)

$\mathrm{SaO}_{2}$ (Postoperative), \%

98 (92-100)

ICU stay, days

7 (2-28)

Death, n 
median length of the intensive care unit (ICU) stay was seven (2-28) days. In-hospital mortality occurred in four (20\%) subjects. Correlation analyses revealed that intraoperative mean arterial pressure was significantly correlated with in-hospital mortality $(r=-0.565, p=0.009)$. No significant correlation was observed between in-hospital mortality and age, gender, comorbid disease, etiology, heart rate, $\mathrm{SaO}_{2}$, and ICU stay.

\section{Discussion}

This retrospective study aimed to demonstrate the singlecenter experience of subjects who underwent surgery for ASDH. The main cause of the ASDH was traumatic in our series. The most frequent comorbid disease accompanying ASDH was hypertension. In-hospital mortality was recorded in $20 \%$ of the subjects, and intraoperative mean arterial pressure was a significant contributor to the mortality rate. Our findings have not shown a correlation between the cause of ASDH and related mortality.

An acute subdural hematoma is one of the most common neurosurgical emergencies with potentially lethal complications ${ }^{[8]}$. Appropriate neurosurgical care is critical to minimize the rate of complications and, eventually, death. Neurosurgical care of a patient with ASDH includes maintenance of oxygenation and adequate blood pressure, the reversal of anticoagulation, intracranial pressure monitoring and maintenance of cerebral perfusion, seizure prophylaxis, analgesia and sedation, deep vein thrombosis prophylaxis, appropriate fluid and nutrition support and stress ulcer prophylaxis $[5,9,10]$.

The mortality rate of the subjects in our series was quite low when compared to the previous data indicating a mortality rate ranging from $55.4 \%$ to $88 \%{ }^{[11,12]}$. However, the mean age of the subjects in our study was lower than that of the previous reports. The relatively younger age of our study population might have positively influenced the mortality rate. This may also be related to significant improvements in the surgical and medical management of these patients compared to patients of the same age in previous decades. Similar to previous evidence, the most frequent comorbid disease accompanying ASDH in our study was hypertension [12]. It has been shown that acute hypertensive crises may lead to spontaneous ASDH. A substantial amount of the subjects analyzed in this study was considered to have an ASDH due to the acute elevation of the blood pressure. However, distinguishing whether the hypertensive crisis happened secondary to the pain from the subdural bleeding, or that the hypertensive crisis caused the ASDH neces- sitates further research.

Adequate arterial pressure is required to maintain cerebral perfusion. Reduction in the intracranial pressure and or evacuation of the hematoma may lead to the onset of the hypotension during surgery ${ }^{[13]}$. This is more prominent in subjects with preoperative hypotension. Elevated systolic blood pressure (>140 $\mathrm{mmHg}$ ) before surgery and intraoperative hypotension ( $<90 \mathrm{mmHg}$ ) has been shown to increase the risk for the development of acute brain swelling [14]. Similar to the findings reported in previous studies, in our study population, a significant reduction in mean arterial pressure has been observed. Moreover, Intraoperative mean arterial pressure was the only significant contributor to in-hospital mortality. Our findings show that perioperative hypotension should be corrected vigorously with fluids and pharmacological agents to maintain cerebral perfusion. In addition, to achieve a steady intracranial pressure reduction, hematoma should be performed slowly and cautiously.

The relatively small sample size, lack of data concerning neurological characteristics and outcomes, and the absence of the imaging data are the major limitations of this study. These results, therefore, need to be interpreted with caution. However, when the paucity of information regarding the surgical management of the subjects with ASDH is considered, our findings provide valuable data for the clinicians.

\section{Conclusion}

In our study population, the mortality from surgical management of the ASDH was $20 \%$, which is quite lower than the reported mortality rate in previous studies. The relatively younger age of our subjects may have an effect on that mortality rate. We also found that intraoperative mean arterial pressure was a significant contributor to in-hospital mortality. Rapid and vigorous management of the intraoperative hypotension may improve the surgical outcomes in subjects with ASDH.

Ethics Committee Approval: Retrospective study.

Peer-review: Externally peer-reviewed.

Authorship Contributions: Concept: E.A.; Design: E.A.; Data Collection or Processing: E.A.; Analysis or Interpretation: E.A.; Literature Search: E.A., M.E.; Writing: E.A.

Conflict of Interest: None declared.

Financial Disclosure: The authors declared that this study received no financial support. 


\section{References}

1. The Brain Trauma Foundation. The American Association of Neurological Surgeons. The Joint Section on Neurotrauma and Critical Care. Indications for intracranial pressure monitoring. J Neurotrauma 2000;17:479-91.[CrossRef]

2. Vega RA, Valadka AB. Natural History of Acute Subdural Hematoma. Neurosurg Clin N Am 2017;28:247-55. [CrossRef]

3. Maxeiner $\mathrm{H}$, Wolff $M$. Pure subdural hematomas: a postmortem analysis of their form and bleeding points. Neurosurgery 2007;61:267-72. [CrossRef]

4. Mulcahy MJ, Chaganti J, Dower A, Al-Khawaja D. Spontaneous Acute Arterial Subdural Hematoma. World Neurosurg 2018;110:403-6. [CrossRef]

5. Won SY, Dubinski D, Bruder M, Cattani A, Seifert V, Konczalla J. Acute subdural hematoma in patients on oral anticoagulant therapy: management and outcome. Neurosurg Focus 2017;43:E12. [CrossRef]

6. Wasfie T, Frisbie J, Ho T, Boyer JJ, Knisely T, Barber KR, et al. Acute Traumatic Subdural Hematoma among the Elderly: Reducing Readmission. Am Surg 2017;83:e231-3.

7. McGinity MJ, Michalek JE, Rodriguez JS, Floyd JR. Surgical evacuation of acute subdural hematoma in octogenarians: a ten-year experience from a single trauma center. Br J Neurosurg 2017;31:714-7. [CrossRef]

8. Bullock MR, Chesnut R, Ghajar J, Gordon D, Hartl R, Newell DW, et al; Surgical Management of Traumatic Brain Injury Author Group. Surgical management of acute subdural hematomas. Neurosurgery 2006;58:S16-24. [CrossRef]

9. Al-Mufti F, Mayer SA. Neurocritical Care of Acute Subdural Hemorrhage. Neurosurg Clin N Am 2017;28:267-78. [CrossRef]

10. Pollandt S, Ouyang B, Bleck TP, Busl KM. Seizures and Epileptiform Discharges in Patients With Acute Subdural Hematoma. J Clin Neurophysiol 2017;34:55-60. [CrossRef]

11. Gan BK, Lim JH, Ng IH. Outcome of moderate and severe traumatic brain injury amongst the elderly in Singapore. Ann Acad Med Singapore 2004;33:63-7.

12. Cagetti B, Cossu M, Pau A, Rivano C, Viale G. The outcome from acute subdural and epidural intracranial haematomas in very elderly patients. Br J Neurosurg 1992;6:227-31. [CrossRef]

13. Tamaki T, Node Y, Yamamoto Y, Teramoto A. Cardiopulmonary hemodynamic changes during acute subdural hematoma evacuation. Neurol Med Chir (Tokyo) 2006;46:219-24. [CrossRef]

14. Saito T, Kushi H, Makino K, Hayashi N. The risk factors for the occurrence of acute brain swelling in acute subdural hematoma. Acta Neurochir Suppl 2003;86:351-4. [CrossRef] 